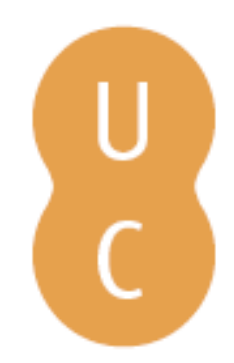

\title{
nommalina
}

\section{Satisfação no trabalho dos bombeiros: a influência das emoções e do coping}

Autor(es): $\quad$ Vara, Natália; Gonçalves, Sónia P.; Queirós, Cristina

Publicado por: Imprensa da Universidade de Coimbra; RISCOS - Associação

URL

persistente: URI:http://hdl.handle.net/10316.2/34961

DOI: $\quad$ DOI:http://dx.doi.org/10.14195/978-989-96253-3-4_161

Accessed : $\quad$ 6-Jan-2015 23:35:05

A navegação consulta e descarregamento dos títulos inseridos nas Bibliotecas Digitais UC Digitalis, UC Pombalina e UC Impactum, pressupõem a aceitação plena e sem reservas dos Termos e Condições de Uso destas Bibliotecas Digitais, disponíveis em https://digitalis.uc.pt/pt-pt/termos.

Conforme exposto nos referidos Termos e Condições de Uso, o descarregamento de títulos de acesso restrito requer uma licença válida de autorização devendo o utilizador aceder ao(s) documento(s) a partir de um endereço de IP da instituição detentora da supramencionada licença.

Ao utilizador é apenas permitido o descarregamento para uso pessoal, pelo que o emprego do(s) título(s) descarregado(s) para outro fim, designadamente comercial, carece de autorização do respetivo autor ou editor da obra.

Na medida em que todas as obras da UC Digitalis se encontram protegidas pelo Código do Direito de Autor e Direitos Conexos e demais legislação aplicável, toda a cópia, parcial ou total, deste documento, nos casos em que é legalmente admitida, deverá conter ou fazer-se acompanhar por este aviso.

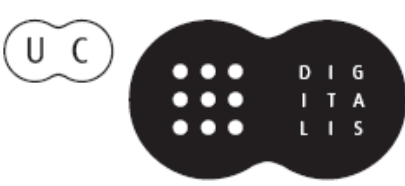



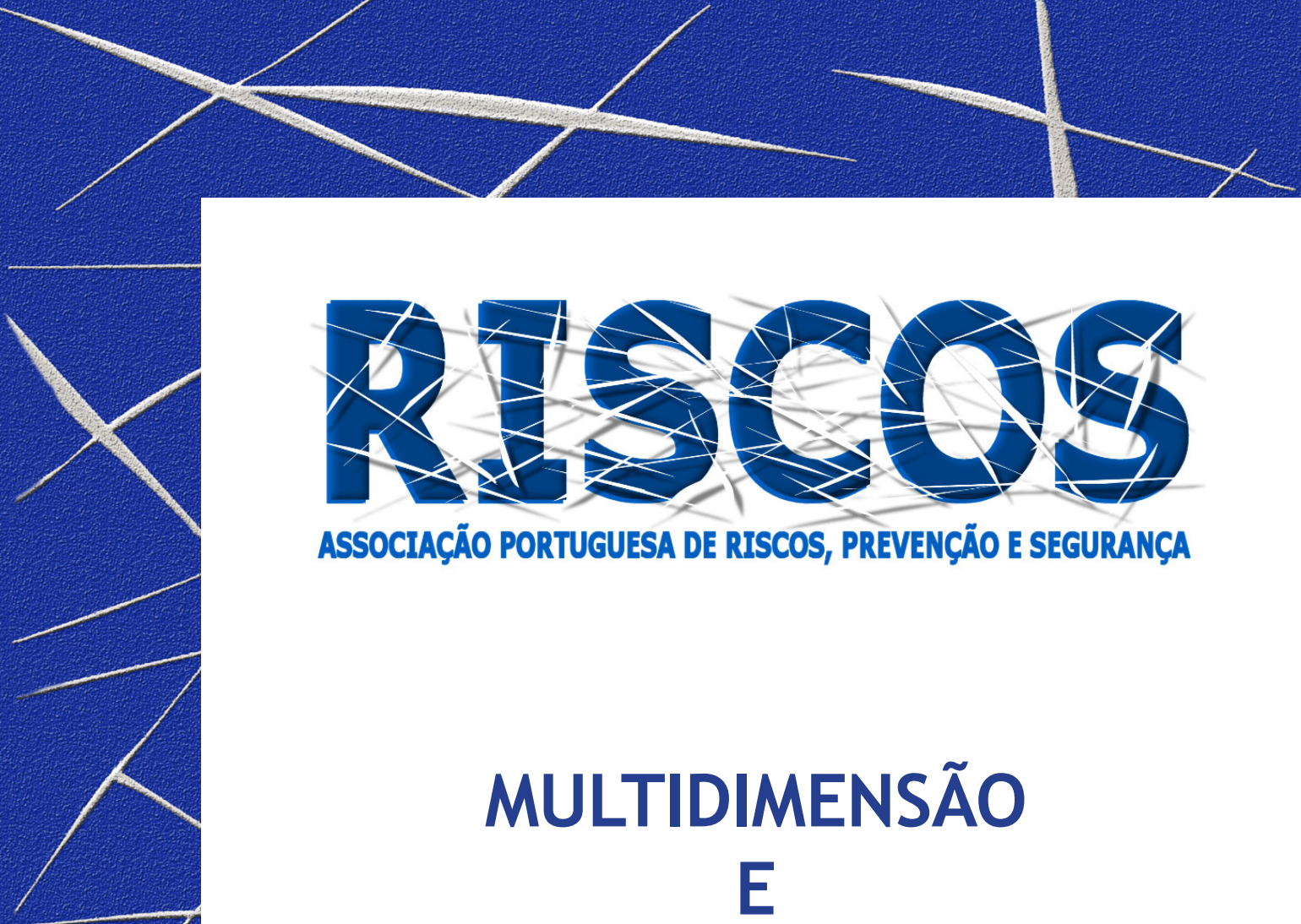

ASSOCIAÇÃO PORTUGUESA DE RISCOS, PREVENCCÃO E SEGURANÇA

MULTIDIMENSÃO

E
TERRITÓRIOS DE RISCO

III Congresso Internacional

I Simpósio Ibero-Americano

VIII Encontro Nacional de Riscos

Guimarães

2014 


\title{
SATISFAÇÃO NO TRABALHO DOS BOMBEIROS: A INFLUÊNCIA DAS EMOÇÕES E DO COPING
}

\author{
Natália Vara \\ Faculdade de Psicologia e de Ciências da Educação da Universidade do Porto; Escola Superior de Saúde do Instituto \\ Politécnico de Bragança \\ vara.natalia@gmail.com \\ Sónia P. Gonçalves \\ Instituto Piaget \\ sonia.goncalves@almada.ipiaget.pt \\ Cristina Queirós \\ Faculdade de Psicologia e de Ciências da Educação da Universidade do Porto \\ cqueiros@fpce.up.pt
}

\begin{abstract}
RESUMO
Os bombeiros estão diariamente expostos a situações stressantes e a uma variedade de emoções que têm de gerir. Estudos reconhecem que as emoções negativas prejudicam a capacidade de trabalho (Galloucis et al., 2000) e o stress laboral, a não satisfação com o trabalho e estratégias de coping pobres, parecem fazer-se acompanhar de um desconforto emocional significativo (Martins, 2004). Este estudo tem como objectivo compreender a influência das emoções expressas no trabalho sobre a satisfação e perceber se esta é mediada pelas estratégias de coping. Os resultados revelaram que a combinação das emoções expressas no trabalho com as estratégias de coping pode aumentar a satisfação profissional e pode conduzir a uma melhor gestão das situações stressantes no trabalho (Folkman \& Lazarus, 1991).

Palavras-chave: Emoções, coping, satisfação, bombeiros
\end{abstract}

\section{Introdução}

A atividade profissional pode proporcionar emoções positivas, realização pessoal e profissional, mas também pode ser uma fonte de stress que gradualmente desgasta. Eleito pela Agência Europeia para a Segurança e Saúde no Trabalho como tema para 2014, o stress, é algo sempre presente na atividade dos bombeiros, nomeadamente, lidar com circunstâncias físicas desagradáveis, vítimas problemáticas, pressão temporal, expectativas dos outros e de si próprios.

Em muitas profissões, incluindo a dos bombeiros, é esperado que os profissionais realizem as tarefas e exerçam esforço físico e mental, mas também lhes é exigida a gestão das suas próprias emoções no contexto de trabalho. Assim, enquanto prestadores de cuidados/serviços se estes profissionais cumprirem com êxito a exigência para exibir e sentir emoções, isso vai ter efeitos positivos, contribuindo para o sentimento de autoeficácia ou realização pessoal (Zapf et al., 2001). Acredita-se que lidar com outras pessoas satisfaz necessidades de afiliação, status e reconhecimento, comuns a um comportamento altruísta característico dos bombeiros, no qual o trabalho emocional desempenha um papel importante como stressor que afeta os profissionais de várias formas. Zapf e colegas (2001) definiram o trabalho emocional como os processos psicológicos necessários para regular as emoções desejadas/impostas pela organização como parte do trabalho ou função. Côté e Morgan (2002) demostraram que amplificando ou exagerando as emoções positivas no trabalho estas podem ter um efeito positivo sobre a satisfação no trabalho. Além disso, outros estudos verificaram que a expressão de emoções positivas e requisitos de sensibilidade estavam positivamente relacionadas com a realização pessoal e satisfação no trabalho (Zapf et al., 2001). Estudos salientam que as emoções interferem com a saúde mental, e, nomeadamente o stress laboral, a vulnerabilidade ao stress, a insatisfação com o trabalho, a fadiga crónica, a ansiedade 
e estratégias de coping pobres, parecem acompanhar-se de um desconforto emocional significativo, contribuindo para o aumento da probabilidade dos profissionais desenvolverem problemas de comportamento (Martins, 2004). Outros autores (Chiavenato, 2010) destacam que a qualidade de vida no trabalho é determinada pelas aspirações da pessoa em relação ao seu bem-estar e satisfação do trabalho, bem como com os interesses da organização e os seus efeitos nos objetivos organizacionais. Parece então existir uma interação entre as características individuais (necessidades, valores, crenças e expectativas) e as organizacionais (estrutura organizacional, recursos, sistemas de recompensas). Assim, se a qualidade de vida no trabalho for pobre, pode originar insatisfação do trabalho e comportamentos desajustados tais como erros de desempenho, absentismo, etc.

A satisfação no trabalho pode ser perspetivada como um estado emocional positivo que resulta da forma como o indivíduo perceciona o seu trabalho (Chiavenato, 2010). A manifestação de um elevado nível de satisfação costuma refletir a existência de um elevado nível de adaptação à tarefa, variando contudo de acordo com a perceção individual de cada trabalhador. No entanto, raramente a avaliação dos resultados e da eficácia organizacional tem em conta as consequências que o trabalho tem para as pessoas que o desempenham (Martins, 2004), apesar de o tipo de trabalho, as relações interpessoais, os papéis desempenhados, os sistemas de progressão na carreira e o estilo de liderança/chefia serem elementos determinantes do bem-estar, da saúde e da satisfação laboral (Bakker \& Demerouti, 2014).

$\mathrm{Na}$ literatura tem sido salientado o papel da emoção no processo de stress e coping. Folkman e Lazarus (1991) definiram as emoções como reações psicofisiológicas complexas e organizadas que resultam de avaliações cognitivas, operando como uma unidade que reflete a qualidade e a intensidade da emoção. Defendem que a emoção e o coping se influenciam mutuamente numa relação dinâmica e recíproca, pois a emoção facilita e interfere com o coping (o qual não é apenas uma resposta à emoção, sendo também influenciado pela avaliação) e, numa perspetiva temporal, o coping pode afetar a reação emocional. A avaliação e o coping são, também, entendidos como mediadores da resposta emocional, e, tendo por base a perspetiva que o coping influencia a relação da pessoa-meio e a resposta emocional, pensa-se que o impacto das emoções expressas no trabalho sobre a satisfação laboral pode ser mediado pelo coping. Este estudo tem como objetivo compreender a influência das emoções expressas no trabalho sobre a satisfação e perceber se esta é mediada pelas estratégias de coping.

\section{Método}

Os dados foram recolhidos numa amostra não-probabilística de 505 bombeiros de diferentes zonas do país, tendo uma média de idades de 33 anos ( $D P=8,5)$, experiência profissional de 11,4 anos $(D P=7,9)$, sendo maioritariamente do sexo masculino $(87 \%)$. Relativamente à situação profissional, $53 \%$ são profissionais (assalariados, sapadores, municipais) e $47 \%$ são voluntários. Foi utilizado um questionário de auto-preenchimento, anónimo e confidencial e os dados foram analisados usando o SPSS 19. O instrumento era composto por uma parte sócio-demográfica que avaliou as características individuais e profissionais, incluindo ainda o Brief COPE (Carver et al, 1989; versão traduzida por Pais-Ribeiro \& Rodrigues, 2004) para avaliar as estratégias de coping, o QST - Questionário de satisfação com o trabalho (Pais-Ribeiro, 2008) e a FEWS - Frankfurt Emotion Work Scales (Zapf et al., 1999; versão traduzida por Vara \& Queirós, 2012) para avaliar as emoções expressas no trabalho. 


\section{Resultados}

Foram encontrados (Tabela I) valores elevados na expressão de emoções positivas, no coping focado no problema e em todas as dimensões da satisfação com o trabalho. Existem correlações positivas significativas entre o expressar emoções positivas e o coping focado no problema e todas as dimensões da satisfação, verificando-se uma correlação negativa entre o expressar emoções negativas e as dimensões da satisfação. Observaram-se ainda correlações positivas significativas entre as emoções negativas e as estratégias de coping focadas nas emoções e no evitamento, sendo também estas últimas as que apresentam mais correlações negativas com as dimensões da satisfação.

Tabela I. Média, Desvio padrão e Correlações entre as dimensões da satisfação, as emoções expressas no trabalho e estratégias de coping

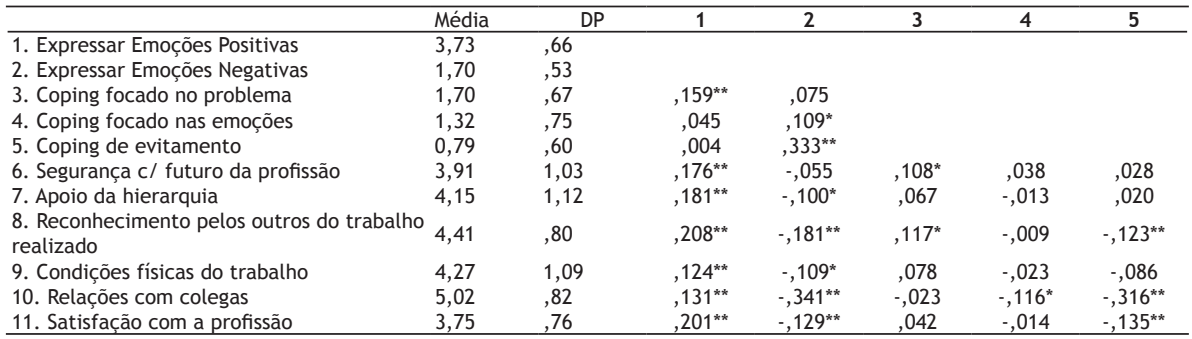

${ }^{*} p<0.05{ }^{* *} p<0.010$ (valores mínimos e máximos das escalas: emoções 1-5; coping 0-3; satisfação 1-6)

Através de análises de regressão linear pelo método enter procurou-se perceber o impacto das emoções e das estratégias de coping na satisfação no trabalho, bem como verificar se as estratégias de coping mediavam a relação das emoções com a satisfação laboral. Verificou-se (Figura 1), que as estratégias de coping não medeiam o impacto das emoções positivas na satisfação no trabalho, sendo também baixo o valor preditor das emoções positivas (apenas explicam 5,2\%) na satisfação e nas estratégias de coping focadas no problema (2,5\%). Verificouse que o coping de evitamento é preditor de uma baixa satisfação no trabalho, pois o valor de Beta é negativo e prediz apenas $2 \%$ da satisfação.

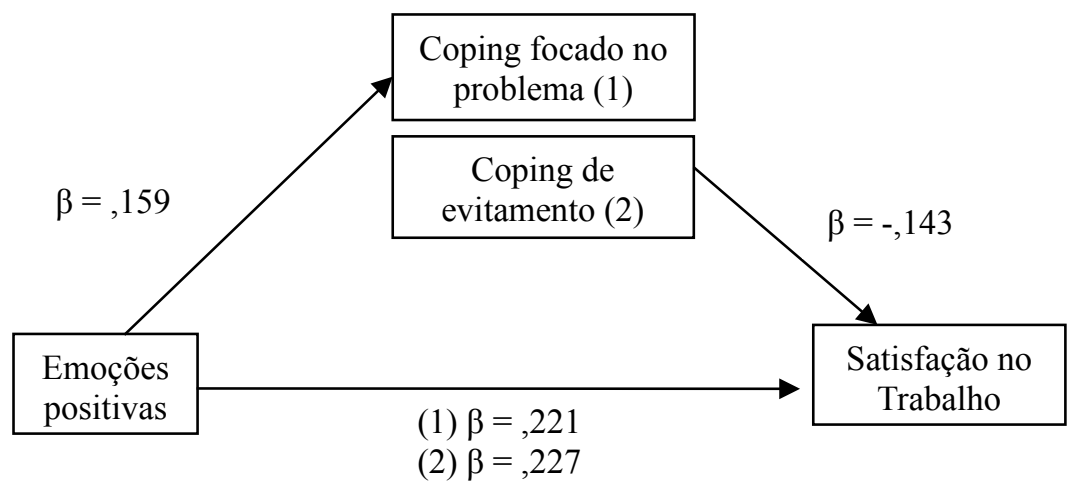

Figura 1. Análise de regressão para os efeitos das emoções positivas sobre a satisfação no trabalho, com mediação das estratégias de coping 
Verificou-se que as emoções negativas são preditoras do uso de estratégias de coping focado nas emoções e do coping de evitamento (explicam 1,2\% e 11\% respetivamente), sendo também preditoras de baixa satisfação no trabalho (Figura 2). 0 coping focado no problema surge relacionado com a satisfação no trabalho mas numa percentagem pouco relevante (1\%).

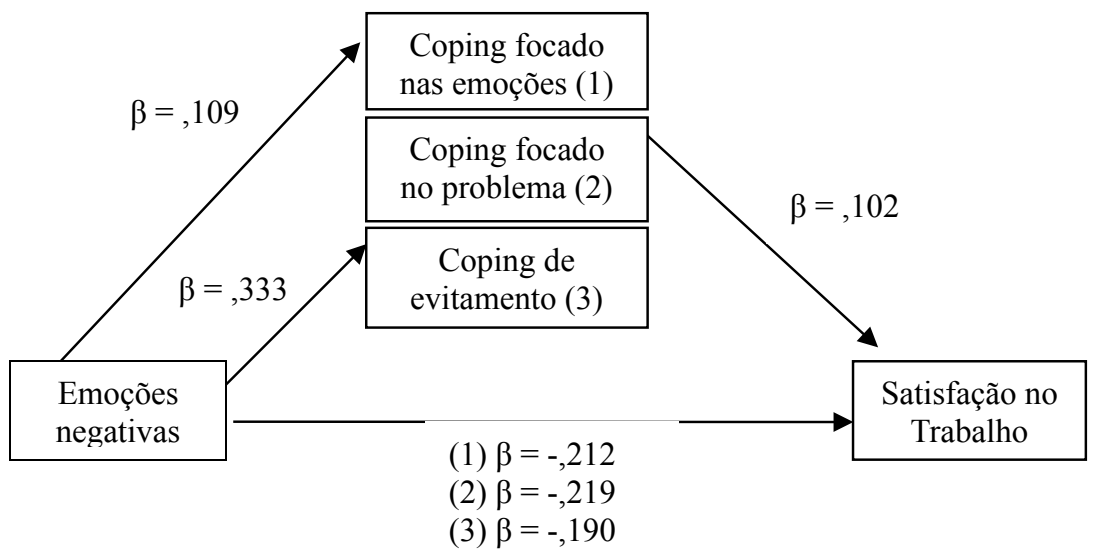

Figura 2. Análise de regressão para os efeitos das emoções negativas sobre a satisfação no trabalho, com mediação das estratégias de coping

\section{Conclusão}

Este estudo abordou as emoções no local de trabalho, o coping e a sua relação com a satisfação, tendo verificado que as emoções positivas vividas no ambiente de trabalho parecem ser preditoras da satisfação e do uso das estratégias de coping focadas no problema. No entanto, não se observou o efeito mediador do coping no impacto das emoções sobre a satisfação no trabalho, apesar de Folkman e Lazarus (1991) defenderem uma relação dinâmica e recíproca de influência entre emoção e coping. Estes resultados alertam ainda para, do ponto de vista prático, se ter em consideração o papel das respostas afetivas na gestão de problemas em várias profissões. Assim, é importante pensar sobre os efeitos do ambiente de trabalho no qual os bombeiros operam, e onde, especialmente as emoções podem surgir e influenciar a satisfação, o stress e o desempenho. Estudos anteriores em que se testou a supressão de emoções revelaram que esta supressão aumentava o stress (Butler et al., 2003), enquanto a amplificação ou exagero de emoções positivas no trabalho parece ter um efeito positivo sobre a satisfação no trabalho (Côté \& Morgan, 2002) e para a o uso de estratégias de coping adequadas para gerir o stress (Millen, 2009). Poderá ser importante incluir na formação dos bombeiros conteúdos sobre gestão do stress e regulação das emoções, bem como criar nos corpos de bombeiros equipas de suporte de pares (ex: modelo CISM) que previnam o trauma, a insatisfação com o trabalho e o stress, num ano em que os riscos psicossociais no trabalho são valorizados.

\section{Bibliografia}

Bakker, A.B., \& Demerouti, E. (2014). Job demands-resources theory. In C. Cooper \& P. Chen (Eds.). Wellbeing: A Complete Reference Guide (pp.37-64). Chichester, UK: Wiley-Blackwell.

Butler, E.A., Egloff, B., Wilhelm, F.H., Smith, N.C., Erickson, E.A., \& Gross, J. (2003). The Social consequences of expressive suppression. Emotions, 3, Washington, p.48-67. 
Chiavenato, I. (2010). Gestão de pessoas: o novo papel dos recursos humanos nas organizações. $3^{\mathrm{a} e d .}$ Rio de Janeiro: Elsevier Editora, 579 p.

Côté, S., \& Morgan, L. (2002). A longitudinal analysis o the association between emotion regulation, job satisfaction, and intentions to quit. Journal of Organizational Behavior, 23, Chichester, p.947-962.

Galloucis, M., Silverman, M., \& Francek, H. (2000). The impact of trauma exposure on the cognitive schemas of a sample of paramedics. International Journal of Emergency Health, 2, Illinois, p. 5-18

Folkman, S., \& Lazarus, R. (1991). Coping and Emotion,. In A. Monat, R. S. Lazarus (Eds.), Stress and Coping, an Antology (pp.207-227). New York, Colombia University Press

Martins, M.C. (2004) - Factores de Risco Psicossociais para a Saúde Mental. Millenium - Educação, Ciência e Tecnologia, Revista do ISPV, 29, Viseu, p.255-268.

Millen, D. (2009). The Ability of Firefighting Personnel to Cope With Stress. Journal of Social Change, 3, Minneapolis, p.38-56

Zapf, D., Seifert, C., Schmutte, B., Mertini, H., \& Holz, M. (2001) - Emotion Work and Job Stressors and their effects on burnout. Psychology and Health, 16, London, p.527-545. 